\title{
A Contabilidade a Serviço do Nazismo: Uma Análise da Utilização da Contabilidade como Instrumento de Exercício de Poder
}

\author{
The Accounting Department of the Nazism: An Analysis of the Use of \\ Accounting as Instrument of Exercise of Power
}

\author{
Octavio Ribeiro de Mendonça Neto \\ Doutor em Contabilidade pela FEA - USP \\ Universidade Presbiteriana Mackenzie \\ Edson Luiz Riccio \\ Professor Doutor do Programa de Pós \\ Graduação em Contabilidade da FEA/USP \\ Universidade de São Paulo
}

\author{
Ricardo Lopes Cardoso \\ Doutor em Contabilidade pela FEA - USP \\ Universidade Presbiteriana Mackenzie \\ Marici Cristine Gramacho Sakata \\ Doutora em Comunicação pela ECA/USP \\ Universidade de São Paulo - USP
}

\section{Resumo}

O presente trabalho analisou a utilização da Contabilidade como um instrumento de exercício do poder por regimes totalitários, em particular pelo regime Nazista implantado na Alemanha em 1933. . O estudo está fundamentado em uma pesquisa bibliográfica interdisciplinar realizada em livros e artigos científicos da época e atuais e tem um caráter historiográfíco crítico. Os resultados obtidos revelam que a Contabilidade contribuiu, no caso do Nazismo, de forma inequívoca para a implantação e perpetuação do regime e da ideologia Nacional Socialista, participando diretamente, sugerindo técnicas e fornecendo pessoal qualificado, contribuindo não só para a condução da economia de guerra, mas também para a perpetração do Holocausto. A principal contribuição do estudo é a de constatar que a prática contábil não é neutra e tem conseqüências sociais, algumas vezes terríveis, como no caso da sua contribuição para a perpetração do Holocausto e, diante dessa constatação aterrorizante, incentivar iniciativas como as propostas por McPhail (2001) no sentido de introduzir a emoção na educação contábil objetivando combater a tendência da Contabilidade de desumanizar o indivíduo.

Palavras - chave: Contabilidade. Poder. Nazismo.

\begin{abstract}
This paper analyzed Accounting as a tool used to exercise power by totalitarian regimes, mainly focused in the Nazi regime established in Germany in 1933. The study followed interdisciplinary bibliographic research in actual and war time books an documents and as a critical historiography design. The results show that Accounting had an unequivocal contribution for the implementation and perpetuation of the Nazi regime with a direct participation in the suggestion of techniques and in the supply of qualified people, not only in the economic of war conduction but also in the perpetration of the Holocaust. The paper's main contributions is the confirmation that the accounting practices aren't neutral practices and have social consequences, sometimes terrible ones, like its contribution to the Holocaust and, in face of those terrible facts, encourage initiatives like the ones proposed by McPhail (2001) of the introduction of emotion in accounting education to oppose to the accounting tendency of people dehumanizing.
\end{abstract}

Key-words: Accounting. Power. Nazism. 


\section{Introdução}

As funções de controle e disclosure da Contabilidade têm sido amplamente discutidas na literatura. No início do século XX, conforme observam Gallassi e Mattessich $(2004,63)$, o predomínio da escola italiana fez prevalecer a função controle. Já na década de 1930, conforme salientam Previts e Merino (1998, 235 a 297), o desenvolvimento do mercado de capitais nos Estados Unidos e a criação da Security Exchange Commission SEC fazem emergir a necessidade de uma maior transparência nos demonstrativos contábeis e consolidam a influência da escola norte-americana de Contabilidade sobre as pesquisas acadêmicas na área. Essa função de disclosure passa a ser considerada em conjunto com a função controle, com alguns autores como Chambers (1974) e Kan (1986) privilegiando a primeira, e outros como Littleton e Zimmerman (1962), Most (1982) e Mattessich (1995) colocando essa dualidade como uma das características principais da Contabilidade. Mais recentemente, Demski, Fellingham, Ijiri e Shyam (2002) retomam esta discussão observando que a contabilidade é um sistema de informações para tomada de decisões e também um instrumento de controle que pode ser definido como uma correspondência entre o que os agentes escolhem fazer e aquilo que os outros agentes esperam que façam em determinadas circunstâncias.

Por outro lado, conforme Chua $(1986,602)$, só a partir do início da década de 1970 é que novas dimensões para a Contabilidade surgiram com o questionamento de seu caráter neutro e com a sua caracterização como prática social por autores como Hopwood (1976 e 1987), Miller (1994) e Belkaoui (1981,1996 e 1997) entre outros. Essas novas dimensões para a Contabilidade surgiram com a utilização de abordagens alternativas de pesquisas que foram classificadas por Baxter e Chua (2003), para o caso da contabilidade gerencial em nonrational design school (sugere que as metas das organizações não são claras nem estáveis), naturalistic research (pretende investigar a prática da contabilidade gerencial em seu contexto diário, ou seja, in situ), radical alternative (pretende mostrar o envolvimento da contabilidade gerencial na criação e perpetuação de uma sociedade desigual), institutional theory (sugere que as formas assumidas pelas práticas da contabilidade gerencial são influenciadas não só por exigências técnicas, mas também por vários ambientes institucionalizados, legal, profissional, regulador, etc.), structuration theory (fundamentada na teoria da estruturação de Giddens (1986) que se preocupa com a interconexão entre a capacidade individual de se fazer escolhas e a reprodução de estruturas sociais), foucauldian approach (fundamentada nas idéias do sociólogo francês Michel Foucault, em particular nos conceitos de arqueologia do saber (1967) e de disciplina (1975) e latourian approach (fundamentada na sociology of translation elaborada entre outros por Bruno Latour (1987), que se preocupa com a construção do conhecimento e cuja idéia central é a de que o conhecimento não é algo gerado por um método científico, mas um produto social.

Já os estudos que adotam uma postura mais crítica em relação à prática contábil, entre eles aqueles que analisam a utilização da Contabilidade como um instrumento a serviço de ideologias autoritárias, adotam na sua maioria o que Chua (1986) denominou critical perspective, o que inclui as pesquisas classificadas acima como radical alternative $\mathrm{e}$ foucauldian approach.

O objetivo deste trabalho é mostrar que além do duplo papel de controle e disclosure que exerce com a intenção de tornar mais transparente e eficiente a atividade econômica e social, a Contabilidade também tem sido utilizada como um instrumento eficaz de exercício do poder na instauração e perpetuação de regimes políticos totalitários e repressores. $\mathrm{O}$ método de pesquisa utilizado é o historiográfico, que visa resgatar os acontecimentos humanos ao longo do tempo com o objetivo de entender as mudanças, contradições e tendências da realidade social. Previts e Merino (2000, 23), ao analisarem o significado 
cultural da Contabilidade nos Estados Unidos, observam que a maior parte dos historiadores classifica seus trabalhos em narrativos e interpretativos. Os narrativos descrevem itens de um fato de forma não-analítica, enquanto que os interpretativos avaliam as relações e fornecem explicações, como é comum nas ciências sociais. Sob esta visão, o presente trabalho pode ser classificado como interpretativo, com uma abordagem crítica. Com relação aos procedimentos técnicos, o presente estudo utiliza a pesquisa bibliográfica e documental.

\section{O Conceito de Poder}

Embora a discussão sobre o conceito de poder não seja o foco desse trabalho, algumas breves considerações a respeito do tema se fazem necessárias para que fique claro como o termo é empregado no presente estudo.

$\mathrm{Na}$ definição de Hobbes, "O poder de um homem consiste nos meios de que presentemente dispõe para obter qualquer visível bem futuro" (HOBBES: 2007, 70) enquanto que Weber $(1954,323)$ conceitua o poder como sendo a possibilidade de alguém impor a sua vontade sobre os demais. Embora essas definições não sejam conflitantes, é a definição weberiana de poder que é aqui considerada, ou seja, quando se declara que o objetivo desse estudo é mostrar que a Contabilidade tem sido utilizada como um instrumento eficaz de exercício do poder na instauração e perpetuação de regimes políticos autoritários e repressores, isso significa que o que se pretende analisar é a utilização da Contabilidade como um instrumento para a imposição da vontade de alguns sobre os demais.

Já o filósofo francês Michel Foucault, cuja extensa obra inclui a análise do poder, enfoca seus estudos não na conceituação de poder, mas principalmente na formas como é exercido. Suas idéias a esse respeito estão expressas principalmente em L'archéologie du savoir (1967), Surveiller et punir (1975) e Truth and juridical forms (2001) e constituem uma sólida base teórica para explicar o uso da contabilidade como instrumento de exercício do poder. Nesse sentido, a Contabilidade pode funcionar como um poderoso instrumento de vigilância e controle no conceito panóptico do termo elaborado pelo autor, que caracteriza a sociedade contemporânea como uma sociedade disciplinar, onde o poder é exercido por uma contínua supervisão sobre o individuo. Essa supervisão possibilita o controle, a punição, compensação e correção, do indivíduo, ou seja sua moldagem e transformação em conformidade com certas normas. Foucault, dessa forma, compara a sociedade moderna com o projeto de uma prisão denominado panóptico proposto em 1791 por Jeremy Bentham.

A idéia do panóptico é a de um edifício circular com uma torre central de vigilância e com as celas em sua circunferência, construído de modo tal que a pessoa na cela não possa nunca saber quando está sendo vigiada. A própria incerteza mental seria um instrumento crucial do método de vigilância. Trata-se, portanto, de uma forma de arquitetura que torna possível um tipo de poder da mente sobre a mente. A partir desta idéia central se desenvolve toda uma teoria de vigilância que apresentaria como vantagem fundamental a aparente onipresença do vigilante.

\section{A Contabilidade a Serviço do Nazismo}

Em 1992, ao analisar as relações entre o estado nazista e as ciências, Beyerchen observava que: "Entre as ciências sociais, a psicologia vem sendo bastante pesquisada. Mas , o que dizer das outras disciplinas, especialmente as ciências econômicas (dada a dedicação dos Nazistas à autarquia) ou administrativas?" (BEYERCHEN, 1992, 615). Ainda hoje, passados mais de quinze anos desta assertiva, a literatura crítica sobre o assunto - ao menos na área da Contabilidade - ainda é modesta e pouco conclusiva, embora alguns estudos 
importantes tenham sido publicados nesse período, trabalhos esses que são analisados ao longo do presente estudo.

\subsection{A Profissão Contábil na Alemanha Nazista}

Em um breve artigo sobre sua participação no $5^{\circ}$ Congresso Internacional de Contabilidade realizado em Berlim em 1938, Matz (1938) relata a situação da profissão contábil na Alemanha após o advento do Nazismo. De acordo com o autor, o contador alemão deve seguir a ideologia do Nacional Socialismo, o que implica que, embora não seja um funcionário governamental, deve zelar para que os interesses da nação tenham prioridade sobre os interesses da empresa para a qual presta serviços. Observa ainda o autor que os contadores passam a fazer parte do que os alemães denominam wirtschaftstreuhänder, categoria que engloba todas as profissões que no mundo dos negócios se caracterizam pela confidencialidade e confiança, e como tal passam a pertencer a duas organizações profissionais distintas; a dos Juristas Nacionais Socialistas e ao Instituto dos Contadores (Institut der Wirtschaftsprüfer - $I d W$ ). A primeira engloba todos os profissionais cujas atividades são de ordem legal, judicial ou confidencial e a segunda, criada em 1934, é o órgão oficial da categoria à qual todos devem se filiar para exercer a profissão.

Embora o relato do autor não teça qualquer comentário de caráter político- ideológico sobre a nova ordem social vigente e sua influência sobre a profissão, a leitura do mesmo sugere que ainda mesmo antes da eclosão da II Guerra, o contador alemão perdeu sua independência e a passou a atuar como um instrumento de exercício do poder do estado Nacional Socialista.

Lippman (2007, 291 a 296) já fornece um panorama bem mais detalhado a esse respeito, ressaltando e criticando de forma veemente o apoio da classe à implantação e perpetuação do regime Nazista. De acordo com o autor, o $I d W$ não foi criado em 1934, como sugere Matz (1938), mas em 1931, pelo próprio governo, e não pelos profissionais e, em 1934, teve seus estatutos alterados para adaptar a profissão ao "Führerprinzip" do Nacional Socialismo, passando a ser administrado por membros leais ao partido. A partir de então se passou a exigir do candidato a membro provas de sua origem ariana, e os judeus e outros indivíduos considerados não-simpatizantes do regime foram impedidos de exercer funções de auditor. Observa ainda que com a adoção do "Führerprinzip" o IdW perdeu sua independência, tornando-se um instrumento do Estado.

Outro aspecto salientado pelo autor refere-se ao apoio da comunidade internacional de contadores à nova situação da profissão na Alemanha, apoio esse materializado pela presença de mais de 300 delegados representando cerca de 30 países no $5^{\circ}$ Congresso Internacional de Contabilidade realizado em Berlim em 1938, época em que a política de perseguição aos judeus já era um fato amplamente conhecido.

Com relação a esse Congresso, Walker $(2000,232)$ observa que a maior delegação estrangeira foi a do Reino Unido. Em seu artigo, Walker (2000), além de traçar um paralelo entre esse evento e os Jogos Olímpicos de 1936 - salientando que ambos foram utilizados pelo governo Nacional Socialista como propaganda do novo regime - analisa também os motivos da maciça participação de delegados ingleses no evento.

Observa o autor que embora essa participação possa ter sido motivada por uma determinação, em consonância com a política do governo inglês de Neville Chamberlain de apaziguar a Alemanha Nazista, em cujo território as firmas de contabilidade inglesas tinham importantes interesses, o fato é que:

“ Ao comparecer ao Congresso e participar das festividades, os contadores Britânicos manifestaram aos seus hóspedes que as principais figures do pais de nascimento da profissão 
nos tempos modernos, não estavam preocupados com a politização da profissão na Alemanha e com as fundações totalitárias do projeto de reprofissionalização Nazista. Dessa forma, os contadores Britânicos ( e Americanos) concederam um aval para o mais amplo estado racista. (WALKER, 2000: 241)

\subsection{O Papel da Contabilidade no Controle da Economia Nacional Socialista.}

Poucos meses após Hitler ter sido nomeado chanceler pelo presidente Hindenburg em 30 de janeiro de 1933, os Nazistas começaram a programar medidas para controlar as atividades econômicas na Alemanha. Em 1939, quando o exército alemão invadiu a Polônia, o modelo de controle adotado pelo governo Nacional Socialista sobre a vida econômica da nação já estava praticamente implantado e as medidas adicionais necessárias posteriormente pelo esforço de guerra limitaram-se a intensificar os controles já em operação (HAMBURGER: 1943, 1). Como se observa a seguir, a Contabilidade desempenhou um papel crucial na viabilização desses controles.

Para os Nazistas, nunca houve dúvida se deveriam ou não controlar os negócios, apenas de que forma o fariam. $\mathrm{O}$ modelo adotado foi um amplo sistema de regulação em lugar da nacionalização pura e simples, ou alguma forma de intervenção direta. Dessa forma, embora não tenham convertido as empresas em organismos estatais e tenham mantido a estrutura privada das mesmas, tanto no aspecto da propriedade como no da gestão, os Nazistas as direcionaram para atender os objetivos do governo Nacional Socialista (HAMBURGER: 1943, 2 a 10).

Por meio desse sistema, passaram a: (a) restringir abertura de novas firmas, dessa forma protegendo as já estabelecidas; (b) proibir a instalação de estabelecimentos de propriedade de judeus; (c) controlar oferta de capital, na sua maior parte direcionado para a indústria de armamentos; (d) controlar a oferta de matérias primas, sujeitas a restrições de importação em função do racionamento de divisas e direcionadas prioritariamente também para a indústria de armamentos; (e) controlar a oferta de trabalho por meio de um sistema de alocação; e (f) controlar preços e salários. (HAMBURGER: 1943, 25 a 62).

Para controlar os preços, os Nazistas passaram a supervisionar a contabilidade das empresas e dos agricultores, o que implicou a obrigatoriedade de manterem livros contábeis a partir de 1938. Embora fosse uma prática comum nas grandes empresas, era uma exceção para o pequeno comércio e para a agricultura. Também estabeleceram padrões, normas e processos contábeis e tornaram obrigatório seu uso. Esses padrões, normas e processos foram baseados no trabalho preliminar da ciência contábil e de gestão alemã, e na experiência de grandes cartéis que já utilizavam práticas uniformes para seus membros.

Um rígido controle de custos foi implantado. Os Nazistas estabeleceram não só quais elementos de custo seriam admitidos na composição do custo unitário total, limitando inclusive o número de horas de trabalho que poderia ser imputado como custo de mão-deobra, mas também a maneira como esses elementos de custos deveriam ser calculados e, em certos casos, os valores máximos admissíveis. Além disso, definiram o lucro não como um resíduo, mas como sendo o montante necessário para cobrir: (a) os impostos; (b) os juros sobre os empréstimos e sobre o capital próprio; e (c) o risco assumido pelo empresário, sendo que os dois últimos itens eram rigidamente controlados. A taxa de juros admitida para o capital próprio era a dos títulos de longo prazo do governo e a base de cálculo excluía qualquer ativo não-operacional, inclusive ações e saldos bancários, enquanto que o retorno do empresário para cobrir o risco do negócio era calculado para mantê-lo alinhado a industria a que pertencia. Uma vez que a definição de lucro incluía os impostos, ela correspondia, na realidade, ao lucro bruto, permitindo dessa forma o controle não só das taxas de lucro mas também do volume dos mesmos por meio dos impostos. Além disso, a alocação desses lucros 
era controlada por intermédio de diversas medidas, entre elas a limitação dos dividendos em dinheiro a 6\% ao ano. (HAMBURGER: 1943, 63 a 74).

Ludmer (1943) descreve algumas medidas adotadas para financiar a economia de guerra Nazista. De acordo com o autor, um primeiro sistema de financiamento funcionou até 1938. De acordo com esse sistema, as encomendas de material militar junto a industria eram pagas com drafts especiais (sonderwechsel). O industrial devia manter esses drafts até esgotar suas reservas para só então descontá-los em seu banco. O banco, por sua vez, deveria manter esses drafts em carteira até também esgotar suas reservas para então redescontá-los no Reichsbank. Esse sistema dependia da existência de reservas privadas.

Um segundo sistema de financiamento funcionou de março de 1938 a março de 1939, quando os drafts deixaram de circular e o financiamento das despesas públicas passou a ser feito pela emissão de títulos e por impostos. Além disso, os judeus foram obrigados a contribuir com um bilhão de marcos. No final desse período, Dr. Schacht - então Ministro da Economia e Presidente do Reichsbank - renunciou, assumindo em seu lugar Dr. Walter Funk, que implementou um terceiro sistema de financiamento.

Funk, antigo membro do partido Nacional socialista, considerou que dada à elevada necessidade de recursos, não poderia contar somente com impostos e títulos públicos, e adotou severas medidas, algumas de caráter puramente expropriatório. Nesse sentido, austríacos, checoslovacos e judeus que possuíssem moeda estrangeira, ações no exterior e jóias eram obrigados a vendê-los para o governo a preço por ele estipulado, e o produto da venda era depositado em uma conta congelada. Como esses recursos não foram suficientes, o governo passou a pagar seus fornecedores com títulos que serviriam no futuro para o pagamento de impostos (taxbonds). Quando esses títulos começaram a ser usados para pagar impostos, a renda do governo começou a diminuir mas foi logo coberta pelo produto de invasões, aumento de impostos e por um rigoroso controle sobre o fluxo de capitais, que incluía a pena de morte. (LUDMER: 1943, 35 a 37)

Matz (1940a e 1940b) apresenta detalhes de algumas das técnicas contábeis utilizadas na implantação dos controles acima descritos. De acordo com o autor, o sucesso do plano quadrienal proposto pelos Nazistas em 1936 exigia como pré-requisito a adoção de uma série de leis e regulamentos, muitas delas relacionadas aos aspectos contábeis. (MATZ: 1940a, 177).

Observa o autor que o comunicado do Ministério da Economia, de 11 de novembro de 1937, impõe regras que estabelecem que o sistema contábil adotado pelas empresas deveria atingir os seguintes objetivos: (a) permitir ao final de cada ano a correta avaliação dos ativos e dos resultados; (b) possibilitar o cálculo dos preços e a supervisão dos custos; (c) possibilitar a supervisão do desenvolvimento e do desempenho da gestão da empresa; e (d) possibilitar o planejamento. Para atingir tais objetivos, o sistema contábil deveria ser constituído de: (a) contabilidade financeira; (b) contabilidade de custos; (c) dados estatísticos para possibilitar análises comparativas e conseqüentemente avaliações de desempenho; e (d) orçamentos. (MATZ: 1940a, 180).

Em um artigo publicado pouco tempo depois Matz (1940b) detalha os Princípios Gerais da Contabilidade de Custos elaborados pelo Conselho de Economia Industrial (Reichsausschuss für Betriebswirstchaft - RfB) e publicados em janeiro de 1939, cujo objetivo declarado era o de contribuir para o crescimento da economia e aprimoramento da performance empresarial. Esse documento estabelece: (a) regras gerais para a construção de um sistema de contabilidade de custos; (b) forma básica de um sistema de contabilidade de custos (custeio por absorção); (c) regras para integração de custos, que além de sugerir o uso do inventário perpétuo determinam a observação do regime de competência para cálculo dos custos; a proibição do lançamento de despesas extraordinárias na formação dos custos e inclusão nos custos de estimativas (as quais deveriam observar uma série de regras restritivas) 
de um pró-labore para o empresário, de uma taxa de risco e de juros para o capital próprio; (d) a inclusão da maior parte possível dos custos no custo direto de forma a minimizar o rateio dos custos indiretos; (e) critérios para a classificação dos custos e sugestão de utilização da departamentalização; (f) separação entre custos fixos e variáveis, o que tornaria transparente a relação custo / emprego.

Em um estudo bem mais recente, Richard (1995, 95 e 96) observa que os trabalhos realizados por Taylor nos Estados Unidos no início do Século XX tiveram uma enorme influência sobre os acadêmicos alemães. Essas idéias sobre a organização científica do trabalho mostraram a necessidade de se abandonar as antigas teorias materialistas e personalistas e de se mudar o foco do pensamento contábil para a contabilidade de custos. Sob a influência de alguns economistas como Marx, esses acadêmicos passaram a construir uma contabilidade baseada no fluxo de capitais (accounting theory based on the circuit). Dessa forma, mesmo antes de os Nazistas chegarem ao poder, já havia uma tendência para a organização científica do trabalho, influenciada por uma geração de pensadores que era hostil aos excessos do sistema de livre empresa então em curso na Alemanha.

Em 1929, Schmalembach publicou um plano de contas que atingiu quatro objetivos fundamentais (RICHARD: 1995, 98): (a) mostrou de forma didática as vantagens da contabilidade de custos; (b) sugeriu uma forma de organizar as grandes empresas com base na descentralização; (c) desenhou um sistema de informações que permite tomada de decisões rápidas; e (d) tornou a contabilidade de custos uma ferramenta útil para a nação.

Embora como anti-taylorista Schmalembach advogasse a descentralização como melhor forma de gerir os negócios e alertasse para os perigos do controle estatal sobre os mesmos, suas idéias foram muitas vezes utilizadas para controlar a economia e serviram de inspiração para o plano de contas imposto compulsoriamente pelos Nazistas para colocar a atividade econômica sob controle do estado. (RICHARD: 1995, 101 a 106).

Essa posição descentralizadora de Schmalembach é ratificada por MATTESSICH e KÜPPER $(2005,361)$ que incluem, em seu artigo, uma citação onde Schmalembach afirma que a adoção de seu plano de contas pelo regime Nacional Socialista foi um erro econômico, uma vez que só faria sentido como ferramenta de gestão por possibilitar uma análise comparativa entre empresas em igualdade de condições de competitividade em um mercado livre, salientando ainda que a interferência do estado na economia só se justifica em situações de extrema urgência.

Em suma, pode-se concluir que a Contabilidade, embora algumas vezes contrariando o objetivo inicial de seus teóricos como no caso de Schmalembach, se constituiu em um instrumento fundamental para colocar a economia alemã sob o controle do estado, contribuindo de forma decisiva para a implantação e perpetuação do regime Nacional Socialista.

\subsection{A Contabilidade e o Holocausto}

$\mathrm{Na}$ abertura da seção de acusação no Tribunal Internacional de Nurenberg em 21 de novembro de 1945, conforme Gilbert $(1961,40)$, o promotor chefe dos Estados Unidos Robert Houghwout Jackson, pronunciou-se a respeito do Holocausto da seguinte forma: "Nunca a História registrou um crime perpetrado contra tantas vítimas ou executado com tanta calculada crueldade".

È no quadro de sua contribuição para a perpetração desse crime monstruoso contra a humanidade que a Contabilidade atinge seu limite extremo como instrumento de exercício do poder e, em conseqüência, de desumanidade dos objetivos da ciência, da administração e de seus praticantes, pois como salienta Arendt (1991), "[...] é da natureza mesma do totalitarismo, e talvez da burocracia, transformar os homens em funcionários, em máquinas 
administrativas, e dessa forma desumaniza-los".Assim, conforme observa Funnell (1998, 435), a análise do Holocausto como uma política deliberada do Estado é uma oportunidade para ampla avaliação do significado social da Contabilidade.

Em sua análise, Hilberg (2006,100 a 113) salienta que a política de destruição dos judeus pela Alemanha Nazista revelou-se um processo desenvolvido em etapas por uma vasta máquina administrativa, sendo cada etapa o resultado de decisões de inúmeros burocratas. Observa, ainda, que embora esse processo tenha se desenvolvido segundo um esquema definível, não havia um plano preestabelecido, ou seja, foi um processo executado passo a passo, e aqueles que executaram as tarefas em 1933 não podiam prever as medidas que seriam tomadas na seqüência.

Os funcionários civis da burocracia estatal, continua o autor, desempenharam um papel importante nesse processo e, nas primeiras etapas, foram seu agente principal: redigiram os decretos que definiram a condição de judeu, organizaram a expropriação de seus bens e determinaram a sua concentração em guetos. A indústria e o setor financeiro também desempenharam um papel fundamental, beneficiando-se das expropriações e da utilização de mão-de-obra escrava. Em suma, destaca o autor, cada setor contribuiu para a realização do processo, não só pelas tarefas que executou, mas pelos métodos administrativos específicos que introduziu nessa máquina de destruição: a burocracia civil introduziu seus hábitos de organização e planejamento, o exército contribuiu principalmente com a insensibilidade característica dos militares. Os empresários também não deixaram de contribuir conforme observou o autor:

"[...] a influência do mundo dos negócios se traduziu, pela grande importância dada à contabilidade, à procura das menores economias, pela recuperação sistemática de todos os subprodutos, da mesma forma que pela eficiência técnica dos centros de execução, calcada naquela das fábricas".(HILBERG: 2006, 107)

Outro aspecto salientado por Hilberg (2006) refere-se à exploração econômica nos campos de concentração pela estrutura implantada a partir de 1940 pelo Obergruppenfüher (general de divisão) Oswald Pohl, que promove, nos mesmos, a instalação de um grupo de empresas com objetivos comerciais, pertencentes à Schutzstaffe - SS (escudo de proteção). Essa organização baseava-se em uma estrutura administrativa que incluía funções tipicamente contábeis como orçamento, finanças e auditoria. (Hilberg: 2006, 1603).

O emprego e a locação de mão-de-obra escrava eram um negócio extremamente lucrativo para a SS, conforme observam Lippman e Wilson $(2007,287)$, que utilizava técnicas de contabilidade gerencial e de custos para mensurar seu resultado. Essas técnicas incluíam a mensuração de resultado econômico da utilização da mão-de-obra escrava. Nessa mensuração, o custo de manutenção dos prisioneiros incluía não só as despesas com alimentação e roupas, mas também a depreciação dos mesmos, para os quais, no caso do campo de Buchenwald, a vida útil era estimada em 9 meses. Para a determinação dos resultados, esses custos eram cotejados com as receitas obtidas, as quais incluíam tanto o resultado do trabalho de cada prisioneiro como o subproduto residual obtido após a morte dos mesmos com a venda de suas roupas, do ouro extraído de seus dentes, da gordura para fabricação de sabão e da utilização das cinzas resultantes da cremação de seus corpos como fertilizante.

Outra ferramenta de gestão utilizada na tomada de decisões, salientam os autores, foi a análise custo/benefício. Segundo eles, os contadores da Alemanha Nazista utilizaram-se dessa ferramenta para comparar o custo de exterminar crianças em câmaras de gás e posteriormente queimar seus corpos ou simplesmente queimá-las até à morte. Com base nos resultados dessa análise decidiram-se pela segunda opção, que resultava em uma economia per capita de 0,10 RM (dez centavos de Reichmarks). 
De acordo com o acima exposto, a burocracia alemã, aí incluídos os contadores, desempenhou um papel relevante na perpetração do Holocausto. A Contabilidade, conforme observa Funnell $(1998,460)$, esteve envolvida em todas as fases do Holocausto, tendo sido utilizada pelos Nazistas como um instrumento para implementar com eficiência uma política de estado que, em um primeiro momento, promoveu a exclusão dos judeus da sociedade alemã, e, em seguida, sua eliminação.

\section{Considerações Finais}

O presente artigo analisou a utilização da Contabilidade como instrumento de exercício do poder pelos regimes totalitários. Embora tenham existido e ainda existam várias formas de regimes totalitários que se instalaram nos mais diversos países ao longo da história, esse estudo limitou-se ao regime Nazista instalado na Alemanha em 1933, e ao regime Fascista italiano.

De acordo com o exposto ao longo do artigo, foi no caso do regime Nazista, instalado na Alemanha em 1933, que essa utilização foi mais exacerbada, servindo a propósitos de uma monstruosidade inimaginável. Nesse caso a Contabilidade contribuiu não só nos aspectos de controle relacionados à economia de guerra, mas também, e o que é monstruoso, à perpetração do Holocausto, crime bárbaro sem precedentes na história da humanidade.

Nesse caso, o governo Nazista montou, com a participação de sua burocracia estatal e privada, de suas forças armadas, de seus intelectuais e acadêmicos e de seus empresários, uma máquina de destruição que eliminou cerca de seis milhões de judeus. Conforme observou Weinreich $(1946,240)$, nenhuma área da ciência que fosse útil ao regime deixou de colaborar na execução desse crime. Salienta que em sua pesquisa sobre a participação dos intelectuais e acadêmicos nos crimes contra o povo judeu surgiram nomes vinculados às mais diversas áreas da ciência que vão desde antropólogos, filósofos, historiadores, juristas e economistas até geógrafos, demógrafos, teólogos, lingüista e médicos.

Os exemplos citados por Lippman e Wilson $(2007,287)$ a respeito da utilização de técnicas de Contabilidade Gerencial para decidir sobre processo mais econômico de execução de crianças mostram até que ponto a ciência esteve envolvida com a barbárie, e colocam em dúvida sua capacidade de contribuir para a evolução da humanidade.

Diante dessa constatação aterrorizante, iniciativas como as propostas por McPhail (2001) no sentido de introduzir a emoção na educação contábil devem ser encorajadas objetivando combater a tendência da Contabilidade de desumanizar o indivíduo.

No que se refere ao fascismo, dada a escassez da literatura sobre o tema, este estudo limitou-se à análise da pesquisa de Cinquini (2003). Essa pesquisa, baseada na produção acadêmica da época, revela uma intenção dos autores italianos em contribuir com a construção da economia corporativa característica da ideologia fascista, mas também uma preocupação com a preservação da autonomia da empresa e de seus princípios de funcionamento.

O levantamento e a análise que compões este estudo sugerem conclusões na mesma linha das colocadas por Funnell (1998), ou seja, a prática contábil não é neutra e tem conseqüências sociais, algumas vezes terríveis, como no caso da sua contribuição para a perpetração do Hocausto.

\section{Referências bibliográficas}

ARENDT, H. (1991), Eichmann à Jérusalem. Paris: Éditions Gallimard, 1991. 
BAXTER, J. e CHUA, W. F. (2003), Alternative management accounting research - whence and whither. Accounting, Organizations and Society v. 28, p. 97-126, 2003.

BELKAOUI, A. R. (1981); Accounting Theory, New York: Harcourt Brace Jovanovich, 1981

(1996) Accounting, a multiparadigmatic science, Westport: Quorum Books, 1996.

(1997); Research perspectives in accounting, Quorum Books, USA, 1997.

BEYERCHEN, A. (1992); What we know about nazism and science. Social Research, Vol. 59, No. 3, p. $615-641,1992$

CHAMBERS, R. J.; (1974) Accounting, evaluation and economic behavior. Houston: Scholars Book Co, 1974.

CHUA, W. F., (1986); Radical developments in accounting thought, The Accounting Review, v.LXI, n.4, October, 1986

DEMSKI, J. S.; FELLINGHAM, J. C.; IJIRI, Y.; SHYAM, S. (2002); Some thoughts on the intellectual foundations of accounting. Accounting Horizons, Jun 2002.

FOUCAULT, M.; (1967); L'archéologie du savoir. Paris: Éditions Gallimard, 1967. .; (1975); Surveiller et punir. Paris: Éditions Gallimard, 1975.

(2001); Truth and juridical forms. In: Power - essential works of Foucault 1954 -

1984. London: Penguin Books, 2001.

FUNNELL, W. (1998); Accounting in The Service of The Holocaust - Critical Perspectives on Accounting, v. 9, n.4, p. 435 - 464, 1998

GALASSI, G. and MATTESSICH, R. (2004); Italian accounting research in the first half of the $20^{\text {th }}$ Century. Review of Accounting \& Finance, v. 3, n. 2, p. $62-83,2004$.

GIDDENS, A. (1986); The constitution of society: outline of the theory of structuration. Berkeley: University of California Press, 1986.

GIBERT, G. M. (1961); Nuremberg Diary. New York: Signet Book, 1961.

HAMBURGER, L. (1943); How Nazi German has controlled business. Washington: The Brookings Institution, 1943

HILBERG, R. (2006); La destruction des juifs d'Europe, 3 Vols. Paris: Éditions Gallimard, 2006.

HOBBES, T. (2007); Leviatã. São Paulo: Editora Martin Claret Ltda., 2007.

HOPWOOD, A. G. (1976); Accounting and human behavior, New Jersey: Prentice Hall, 1976.

(1987); The Archaeology of accounting systems. Accounting Organizations and Society, v.12, n. 3, p. $207-234,1987$

KAN, V. (1986); Accounting theory. New York: John Wiley \& Sons, 1986.

LATOUR, B. (1987); Science in action. Cambridge: Harvard University Press, 1987.

LIPPMAN E. J. and WILSON P. A. (2007); The culpability of accounting in perpetuating the Holocaust. Accounting History, v. 12, n.3, p. 283 - 303, 2007.

LITTLETON, A.C. and ZIMMERMAN, V. K. (1962); Accounting theory: continuity and change. Englewood Cliffs: Prentice - Hall, Inc., 1962.

LUDMER, A. H. (1943); German Financial Mobilization. Accounting Review. v. 18, n. 1, p. $34-39,1943$.

MCPHAIL, K. (2001); The other objective of ethics education: re-humanizing the accounting profession - a study of ethics education in law, engineering, medicine and accountancy. Journal of Business Ethics. n. 34, p. 279-298, 2001.

MATTESSICH, R. (1995); Critique of accounting. Westport: Quorum Books, 1995.

MATTESSICH, R.; GALASSI, G. (2004); Italian accounting research in the first half of the $20^{\text {th }}$ Century. Review of Accounting, and Finance. v.15, n. 3, p. $345-410,2004$. 
MATTESSICH, R.; KÜPPER, H. U. (2005); Twentieth Century accounting research in the German language area. Accounting, Business \& Financial History. v.3, n. 2, p. $62-83$, 2005.

MATZ, A. (1938); The position of the German accountant. Accounting Review, v. 13, n.4, p. $392-395,1938$

(1940 a); Accounting as a tool for economy in German business. Accounting Review, v. 15, n.2, p. $177-183,1940$

1940

(1940 b); Cost accounting in Germany. Accounting Review, v. 15, n.3, p. 371 - 379,

MOST, K. S. (1982); Accounting theory, 2 nd ed. Columbus: Grid Publishing, Inc., 1982.

MILLER, P. (1994); Accounting as social and institutional practice: an introduction. In:

Accounting and institutional practice. Edited by HOPWOOD, A. G. and MILLER, P.

New York: Cambridge University Press, 1994

PREVITS, G. J. and MERINO, B. D. (1998); A history of accountancy in the United States. USA: Ohio State University Press, 1998.

RICHARD, J. (1995); The evolution of accounting chart models in Europe from 1900 to 1945: some historical elements. The European Accounting Review, v.4; n. 1, p. 87 -

WALKER, S. P. (2000); Encounters with Nazism: British accountants and the fifth international congress on accounting. Critical Perspectives on Accounting, v.11, n. 2, p.215-245, 2000.

WEBBER, M. (1954); Max Weber on law in economy and society. Cambridge: Harvard University Press, 1954

WEINREICH, M. (1946); Hitler's professors: the part of scholarship in Germany's crimes against the Jewish people. New York: Yiddish Scientific Institute - YIVO, 1946. 